\title{
EXPOSURE TO WIDESPREAD ENVIRONMENTAL TOXICANTS AND CHILDREN'S COGNITIVE DEVELOPMENT AND BEHAVIORAL PROBLEMS
}

\author{
JOANNA JUREWICZ, KINGA POLAŃSKA, and WOJCIECH HANKE
}

Nofer Institute of Occupational Medicine, Łódź, Poland

Department of Environmental Epidemiology

\begin{abstract}
Nowadays a special attention is focused on prenatal and childhood exposures to a variety of contaminants in the environment, especially toxicants widely present in the environment and their impact on children's health and neurodevelopment. This article aims at evaluating the impact of exposure to several widespread toxicants including: polycyclic aromatic hydrocarbons (PAHs), phthalates, bisphenol A, brominated flame retardants and gas cooking on children's cognitive development and behavioral problems by reviewing most recent published literature. Epidemiological studies focusing on exposure to widespread toxicants and children's development for the last eleven years were identified by a search of the PubMed, Medline, Ebsco and Toxnet literature bases. The combination of following key words was used: 1) referring to the exposure: pregnancy, prenatal exposure, postnatal exposure, gas cooking, exposure to phthalates, bisphenol A, brominated flame retardants, PAHs and 2) referring to outcome: neurodevelopment, neurobehavior, psychomotor development, behavioral problems, cognitive development, mental health, school achievements, learning abilities. The results from the presented studies suggest that there are strong and rather consistent indications that the developing nervous system is particularly vulnerable to insult from low levels of exposure to widespread environmental contaminants such as: phthalates, bisphenol A, brominated flame retardants, polycyclic aromatic hydrocarbons, gas cooking. Considering the suggested health effects, more epidemiologic data is urgently needed and, in the meantime, precautionary policies must be implemented.
\end{abstract}

Key words:

Widespread environmental toxicants, Children, Cognitive development, Behavioral problems

\section{INTRODUCTION}

Nowadays a special attention is focused on prenatal and childhood exposures to a variety of contaminants in the environment, especially toxicants widely present in the environment and its impact on children's health and neurodevelopment.

This interest is sparked partly by a growing recognition of an apparent increase in the incidence of developmental disabilities. Infants and children are especially vulnerable to environmental toxicants because [1]:
- children experience greater exposures by eating, drinking and breathing more per pound of body weight than adults,

- children's metabolic systems are immature and the ability to metabolize, detoxify and excrete many toxicants is different from adult system,

- children's rapidly growing developmental processes are easily disrupted,

- children have more years of life remaining over which to develop chronic diseases.

Received: March 8, 2012. Accepted: July 25, 2012.

Corresponding author: J. Jurewicz, Department of Environmental Epidemiology, Nofer Institute of Occupational Medicine, św, Teresy 8, 91-348 Łódź, Poland (e-mail: joannaj@imp.lodz.pl). 
Genetic, environmental, and social factors interacting in complex ways are important determinants of cognitive development and behaviour. None of those factors alone is sufficient to explain population neurodevelopmental abnormalities. Except for single-gene disorders, heredity accounts for, at most, about $50 \%$ of the variance of cognitive, behavioral, and personality traits among individuals [2]. This, of course, implies that the other $50 \%$ of variability must be due to environmental influences.

Synthetic materials are produced in great volume in industrialized countries. Many of those chemicals have been called into question regarding their safety and potential harmful effects on children's health. Exposures to variety of known and suspected neurodevelopmental toxicants that are widely present in consumer products, food, the home and wider community may also considerably affect children's neurodevelopment.

The aim of this review is to assess the potentially harmful impact of foetal and childhood exposure to several widespread toxicants including: polycyclic aromatic hydrocarbons (PAHs), indoor air pollution from gas cooking, phthalates, bisphenol A and brominated flame retardants on children's cognitive and behavioral development .

\section{CRITERIA FOR INCLUSION OF STUDIES INTO THE REVIEW}

Epidemiological studies focused on the exposure to environmental factors and children's neurodevelopment were identified by a search of the Pubmed, Medline, Ebsco and Toxnet literature databases. The combination of following key words was used:

- referring to the exposure - pregnancy, prenatal exposure, postnatal exposure, gas cooking, exposure to phthalates, bisphenol A, brominated flame retardants, PAHs;

- referring to outcome - neurodevelopment, neurobehavior, psychomotor development, behavioral problems, cognitive development, mental health, school achievements, learning abilities.

Relevant studies were also identified via review of references cited in all published studies. From each study, the following information was abstracted: study design and population, assessment of neurodevelopment (including neurodevelopmental test used), exposure and methods used for its assessment (including biomarkers) and confounding factors. Finally, in this review were included human studies published in peer reviewed journals since 2000. The year was chosen because there were few studies conducted on children's neurodevelopment associated with exposure to environmental factors prior to 2000. At that time the availability of sensitive, specific, and affordable bioassays made biomarkers feasible for use in epidemiological studies for measuring exposures to environmental factors. Simultaneously, growing rodent literature provided convincing hypotheses on the children's neurodevelopmental problems and exposure to environmental factors.

In summary, out of total 100 articles identified, 24 meet eligibility criteria and have been included in the present review.

\section{EXPOSURE TO PHTHALATES AND CHILDREN'S NEURODEVELOPMENT}

Phthalates are a family of industrial chemicals that have been used for a variety of purposes. They are added to plastics in the manufacture of children's toys and medical devices to make them soft and flexible as well as to cosmetics as a vehicle for fragrance. Phthalates are also found in adhesives and glues, agricultural adjuvants, building materials, personal-care products, detergents, paints, pharmaceuticals, food products and textiles. Because phthalates are ubiquitous in daily life, the potential consequences of human exposure to phthalates have raised concerns in the general population and have been studied 
in susceptible subjects such as pregnant women, infants, and older children [3].

As experimental studies suggest that higher levels of di-(2ethylhexyl) phthalate (DEHP) exposure may adversely affect neurobehavioral parameters in mice [4], there is growing concern about the adverse effects of phthalates on children's neurodevelopment.

Exposure to phthalates have been examined in relation to neurodevelopment among neonates 5 days of birth [5], and 5 weeks [6] in the United States, in Korea in children at 6 months and children from elementary schools [7,8], in the United States among children 4-9 years [9] and 3.6-6.4 years of age [10]. One study (also conducted in the United States) has assessed social impairment in children 7 and 9 years old exposed to phthalates [11] (Table 1).

In the study performed among neonates enrolled in a multiethnic birth cohort at the Mount Sinai School of Medicine in New York City, maternal urinary concentrations of phthalate metabolites and neonatal behaviour assessed within 5 days of birth using the Brazelton Neonatal Behavioral Assessment Scale were evaluated. There were strong, inverse associations between increasing concentrations of high molecular weight phthalate metabolites, such as monobenzyl phthalate (MBzP), mono-(2-ethyl-5-carboxypentyl) phthalate (MECPP), mono-(2-ethyl-5-hydroxylhexyl) phthalate (MEHHP), mono-(2-ethyl-5-oxo hexyl) phthalate (MEOHP), mono-(2-ethylhexyl) phthalate (MEHP), mono-(3-carboxypropyl) phthalate (MCPP), and concentration and orientation scores among girls. Similarly, there was an inverse association between high molecular weight metabolite concentrations and quality of alertness scores among girls. Among boys, there appeared to be a slight positive association between increasing low molecular weight metabolite concentrations (monomethyl phtalate - MMP, monoethyl phthalate - MEP, monobutyl phthalate - MBP, monoisobutyl phthalate - MiBP) and motor performance [5].
Significant associations between prenatal exposure to phthalates and infant neurobehavioral outcomes at 5 weeks was found in the study performed in United States, Cincinnati, Ohio. Higher total dibutyl phthalate (DBP) metabolites were associated with improved behavioral organization evidenced by decreased arousal $(p=0.04)$, increased self-regulation ( $\mathrm{p}=0.052$ ), and decreased handling ( $p=0.02)$. In males, higher total di-2-ethylhexyl phthalate (DEHP) metabolites were associated with more nonoptimal reflexes (any nonoptimal response to reflex elicitation) $(p=0.02)[6]$.

An inverse association between prenatal exposure to phthalates and the mental development (MDI) and psychomotor development (PDI) scores of infants at 6 months was observed among 460 children in South Korea [8]. In this study a strong inverse association for male infants between all measured phthalate metabolites (MEHHP, MEOHP, and MBP) were observed [8].

The association of prenatal phthalate exposure with behaviour and executive functioning at 4-9 years of age was examined in multiethnic prenatal population in New York City. However, in multivariate adjusted models, increasing $\log _{\mathrm{e}}$ concentrations of low molecular weight phthalate metabolites (MBP, MEP, MiBP, MMP) were significantly associated only with conduct problems $(\mathrm{OR}=2.40 ; 95 \% \mathrm{CI}$ : 1.34-3.46) [9]. Another study performed in United States (university hospital clinics in Los Angeles, Minneapolis, Columbia, Iowa City) assessed the play behaviour in relation to phthalate metabolites (MEHP, MEHHP, MEOHP, ¿DEHP, mono-n-butyl phthalate (MNBP), MiBP, ¿DBP) concentration in prenatal urine samples. Concentrations of phthalate metabolites measured in mid-pregnancy urine samples were associated with a decreased (less masculine) composite score in boys [10].

The study among 667 elementary schools children in South Korea evaluated relationship between the urine concentrations of the metabolites of DEHP, and dibutyl phthalate (DBP) and children's vocabulary scores. Among 


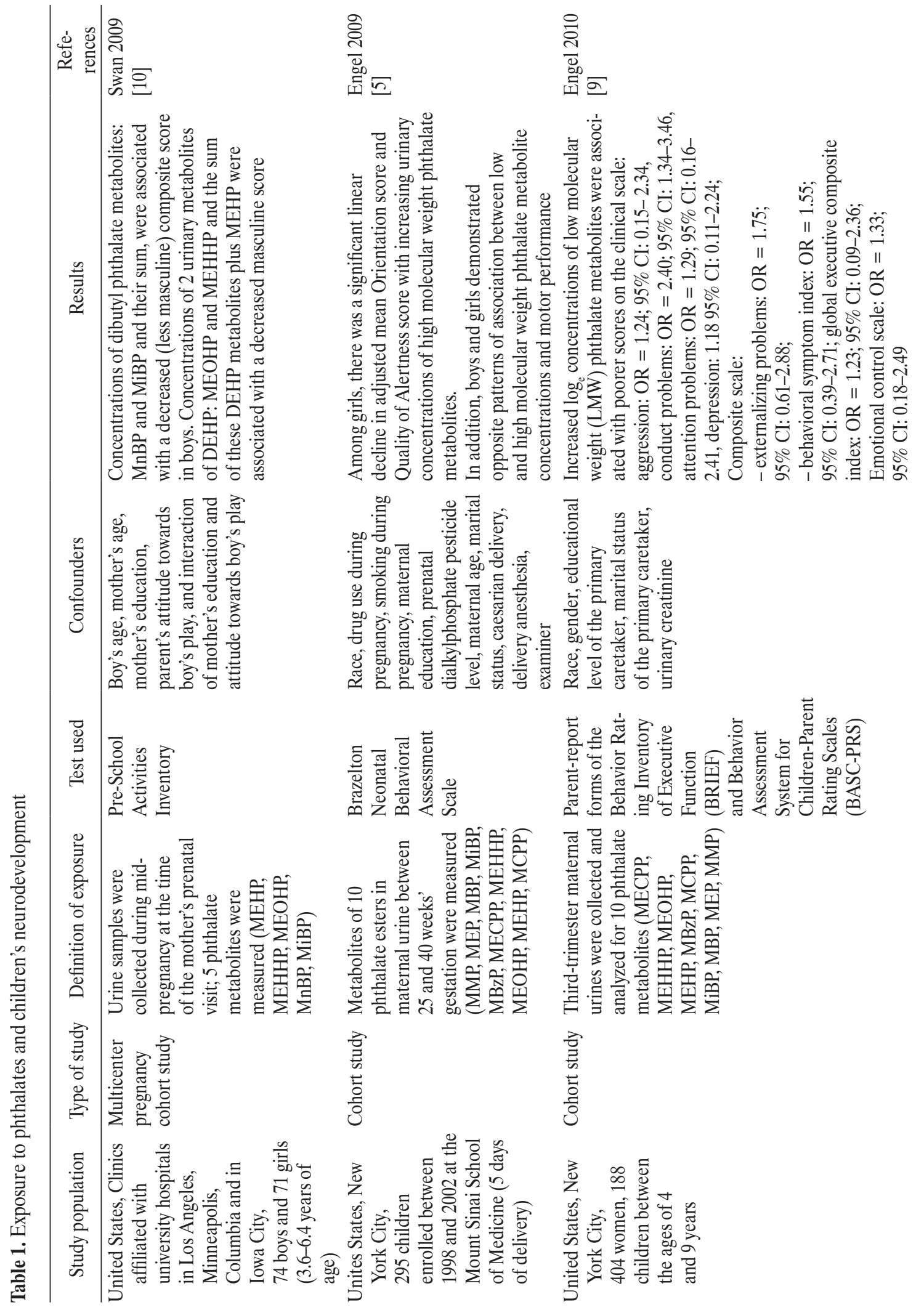


을

를

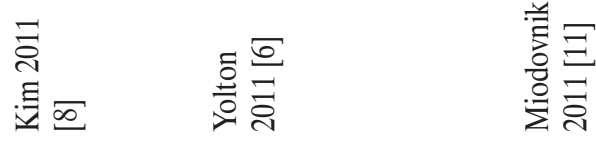

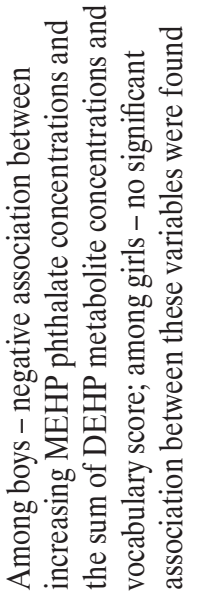

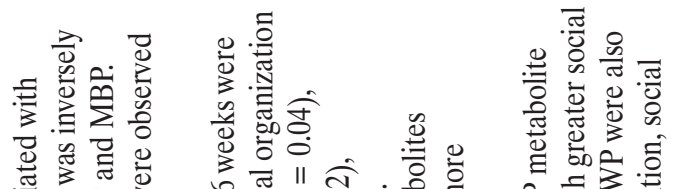

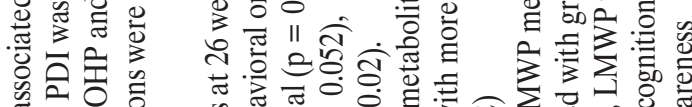

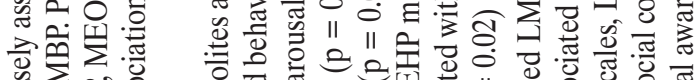

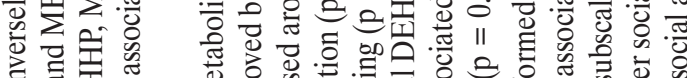

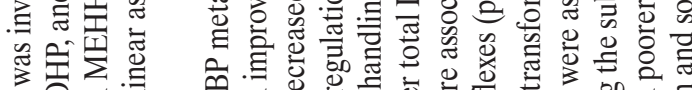

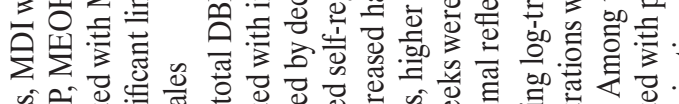

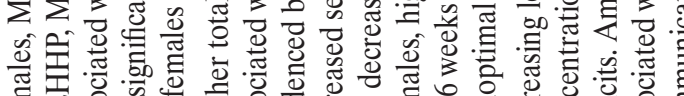

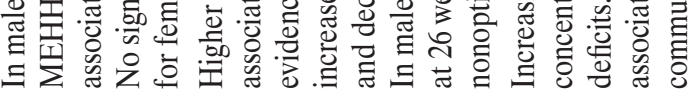

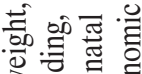

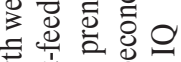

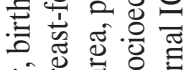

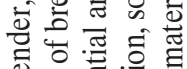

品 0 .

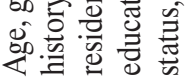

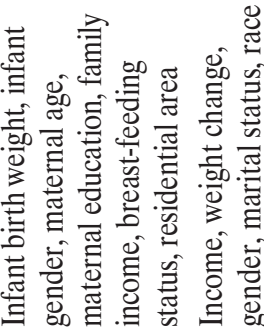

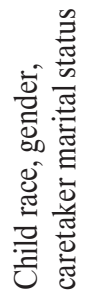

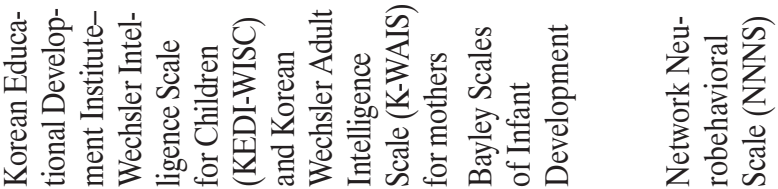

容䨠

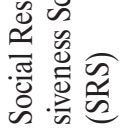

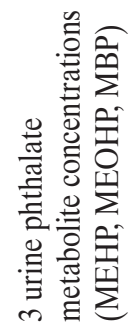

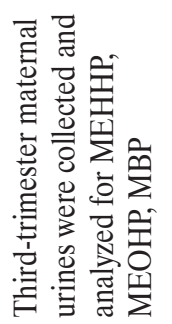

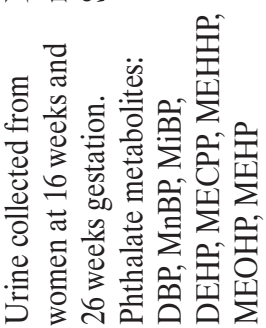

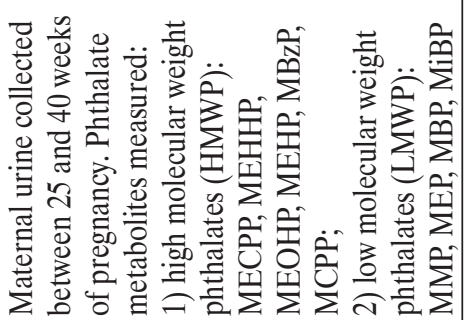

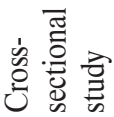

总

总

窟

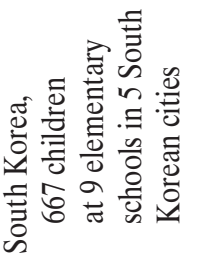

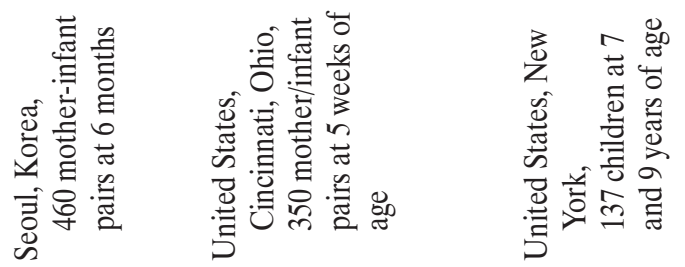

过

总晋

危

.

永

鲜

울

蛋

를

窟

호

ํํㅇ

吾 :

ํํㄹำ

1 पे

옹응

$\Sigma$

氙苍

可

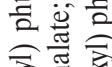

可 장

들

흥 힌

is 일

iे

한 牙

送

奇焉

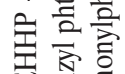

$\sum$ ह

氙

正夜

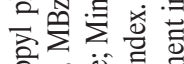

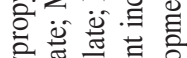

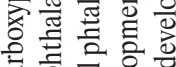

흥 흘 웡

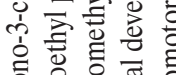

㔄

1 是焉

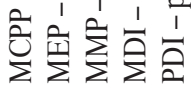


boys, but not girls, a negative association was found between the sum of DEHP metabolite concentrations and vocabulary score [7].

In the assessment of children social impairment, increasing log-transformed low molecular weight (LMW) phthalate metabolite concentrations were associated with greater social deficits. Among the subscales, LMW phthalates were also associated with poorer social cognition, social communication and social awareness [11].

The findings of the studies reviewed indicate that children's exposure to phthalate metabolites (MBzP, MECPP, MEHHP, MEOHP, MEHP, MCPP, MMP, MEP, MBP, MiBP, $\Sigma$ DEHP, $\Sigma$ DBP) may bring about impairments in the neurodevelopmental processes. The observed risks are generally presumed to be related to the endocrine altering properties of these chemicals $[5,10]$. In all the studies, exposure to phthalates was associated with neurodevelopmental disorders: conduct problems [9], quality of alertness among girls [5], decreased (less masculine) composite score in boys [10] and lower concentration and vocabulary score among boys [7]. In the study performed in South Korea an inverse association between prenatal exposure to phthalates and the MDI and PDI scores was observed for boys [8]. The phthalate exposure was associated also with children's social impairment [11].

\section{EXPOSURE TO BPA}

\section{AND CHILDREN'S NEURODEVELOPMENT}

Bisphenol A (BPA), 2,2-bis(4-hydroxyphenyl)propane, is made by combining acetone and phenol. It has estrogenic activity and is acutely toxic to aquatic organisms. BPA is used mainly as a material for the production of epoxy resins and polycarbonate plastics. Due to an increase in products based on epoxy resins and polycarbonate plastics, human exposure to BPA has increased [12]. Bisphenol A can be found in toys, water supply pipes, medical tubing, and food container linings, eyeglass lenses, sports safety equipment, dental monomers, medical equipment and tubing, and consumer electronics.

Five studies have examined the association between BPA exposure and neurodevelopment: four in children [11,1315] and one among infants [6] (Table 2). In the study in Cincinnati, Ohio (USA) no association between mean urinary BPA concentrations and behaviour scores among children, at 2 years of age, was found. However, an association between mean prenatal BPA concentrations and externalizing scores in females was observed [13]. The same author continued the study and examined the children at 3 years of age [14]. Gestational BPA exposure was associated with higher scores for measures of anxiety, hyperactivity, emotional control, and behavioral inhibition. Similar to previous findings [13], the effects of gestational BPA exposure on these behavioral domains were larger among girls than boys [14].

One mother from the study presented above had a urinary BPA concentration of $583 \mu \mathrm{g} / \mathrm{g}$ creatinine at 27 weeks of pregnancy, which was the highest concentration observed in this cohort (median: $2.0 \mu \mathrm{g} / \mathrm{g}$ creatinine) [15]. Her male infant presented abnormalities in neurobehavioral assessment at 1 month of age. Subsequently, the child had normal neurobehavioral testing results at annual evaluations from 1 to 5 years of age [15].

Prenatal exposure to BPA was not significantly associated with neurobehavioral outcomes at 5 weeks in the study performed in Cincinnati, Ohio, United States [6]. Also in the Mount Sinai Children's Environmental Health Study no significant association between BPA exposure and children social impairment at 7 and 9 years of age was observed [11].

Summing up, the results of the studies which examine the association between exposure to BPA and children's neurodevelopment are inconsistent. Studies among children at 2 years of age have indicated the association between prenatal BPA concentrations and externalizing scores in females [13] and at 3 years of age gestational BPA 


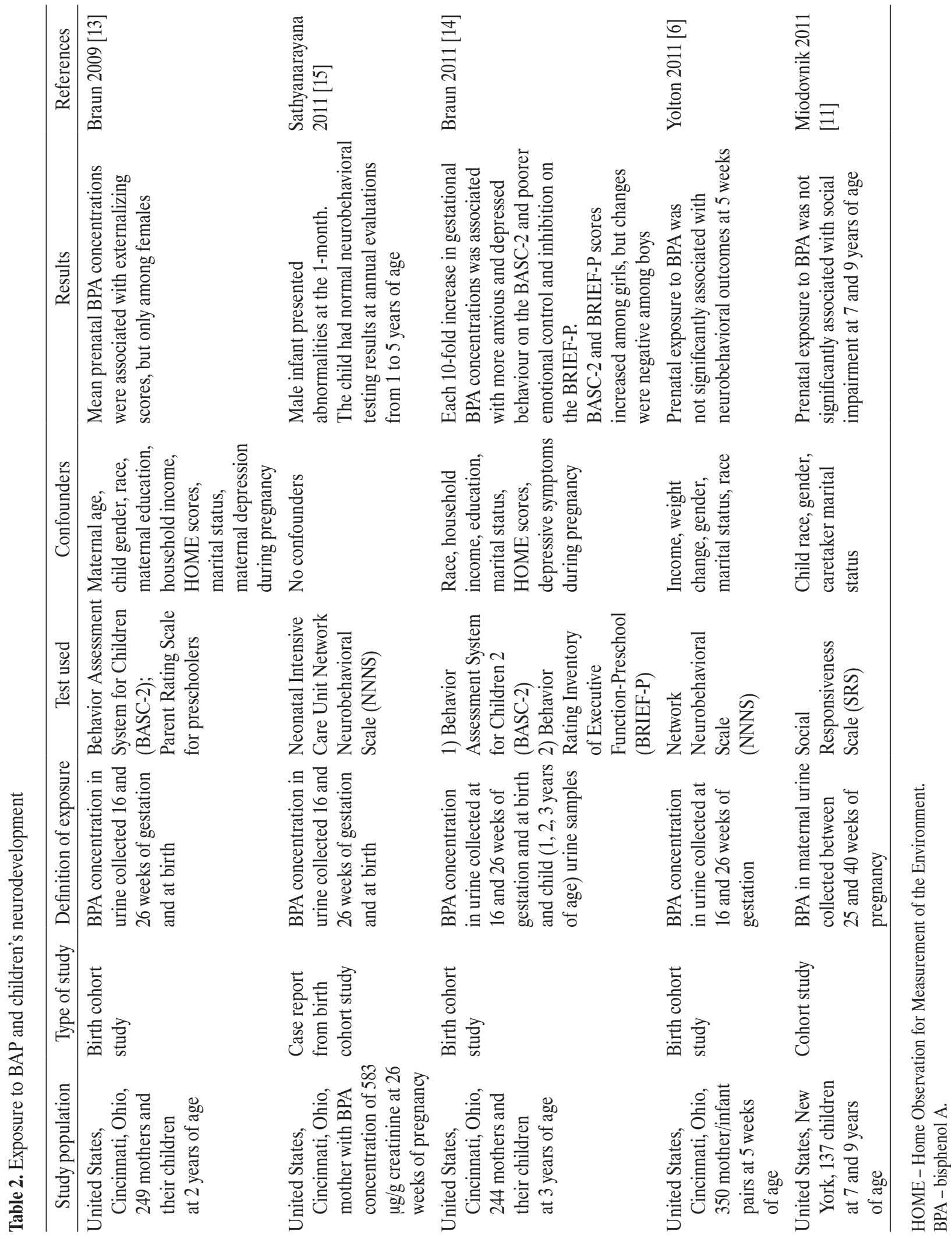


exposure was associated with higher scores for measures of anxiety, hyperactivity, emotional control, and behavioral inhibition [14]. No significant association was observed with neurobehavioral outcomes at 5 weeks infant [6] and social impairment at 7 and 9 years of age [11]. As the results of the presented studies are inconsistent, the relationship should be further examined in epidemiological studies.

\section{EXPOSURE TO BFRs}

\section{AND CHILDREN'S NEURODEVELOPMENT}

Brominated flame retardants (BFRs) are organobromide compounds such as: polybrominated biphenyls (PBBs) and polybrominated diphenyl ethers (PBDEs) [16]. BFRs are commonly used in electronic products as a means of reducing the flammability of the product. The effect of exposure to brominated flame retardants on neurodevelopmental outcomes in children were investigated in two studies: in Netherlands [16] and United States (New York City) [17] (Table 3).

The neuropsychological functioning in Dutch children was assessed at 5-6 years of age. Brominated flame retardants correlated with poorer fine manipulative abilities, poorer attention, better coordination, better visual perception, and better internalizing behaviour [16]. In the study in New York City children with higher concentrations of 2,2,2',4,4'-tetraBDE (BDE 47) (above $11.2 \mathrm{ng} / \mathrm{g}$ lipid), 2,2',4,4',5-pentaBDE (BDE 99) (above $3.2 \mathrm{ng} / \mathrm{g}$ lipid) and 2,2',4,4',6-pentaBDE (BDE 100) (above 1.4 ng/g lipid) scored lower on tests of mental and physical development at 12-48 and 72 months. Associations were significant for 12-month Psychomotor Development Index (BDE-47), 24-month Mental Development Index (MDI) (BDE-47, 99, and 100), 36-month MDI (BDE-100), 48-month full-scale and verbal IQ (BDE-47, 99, and 100) and performance IQ (BDE-100), and 72-month performance IQ (BDE-100) [17].
The result of the presented studies indicate that exposure to brominated flame retardants may result in impaired children's neurodevelopment manifested by poorer fine manipulative abilities, poorer attention [16] and lower scores on tests of mental and physical development [17].

\section{EXPOSURE TO PAHS}

\section{AND CHILDREN'S NEURODEVELOPMENT}

Polycyclic aromatic hydrocarbons (PAHs) are released to air during incomplete combustion and/or pyrolysis of fossil fuel, tobacco, and other organic material [18]. Major sources of PAHs in urban ambient air include fossil fuel combustion by motor vehicles, residential heating units, power plants and industrial activities. Environmental tobacco smoke is the major sources of PAHs in indoor air. PAHs have been shown to be neurodevelopmental toxicants in experimental studies [19-21]. There are $8 \mathrm{hu}$ man epidemiological studies which have examined an association between exposure to PAHs and children's development [22-27], one study has investigated how polymorphism in PAH metabolic genes affects child cognitive development [28], and another one has assessed the combined exposure to environmental tobacco smoke (ETS) and PAH-DNA adducts after the World Trade Center catastrophe and its impact on child development [29] (Table 4).

To evaluate the effects on child mental and psychomotor development of prenatal exposure to airborne PAHs monitored during pregnancy by personal air sampling, a study of nonsmoking African-American and Dominican mothers and children in New York City was performed by Perera and co-workers [22]. Prenatal exposure to PAHs was not associated with psychomotor development index or behavioral problems. However, high prenatal exposure to PAHs (above the $17.96 \mathrm{ng} / \mathrm{m}^{3}$ ) was associated with lower mental development index at age 3. The cognitive developmental delay was also significantly greater for children 


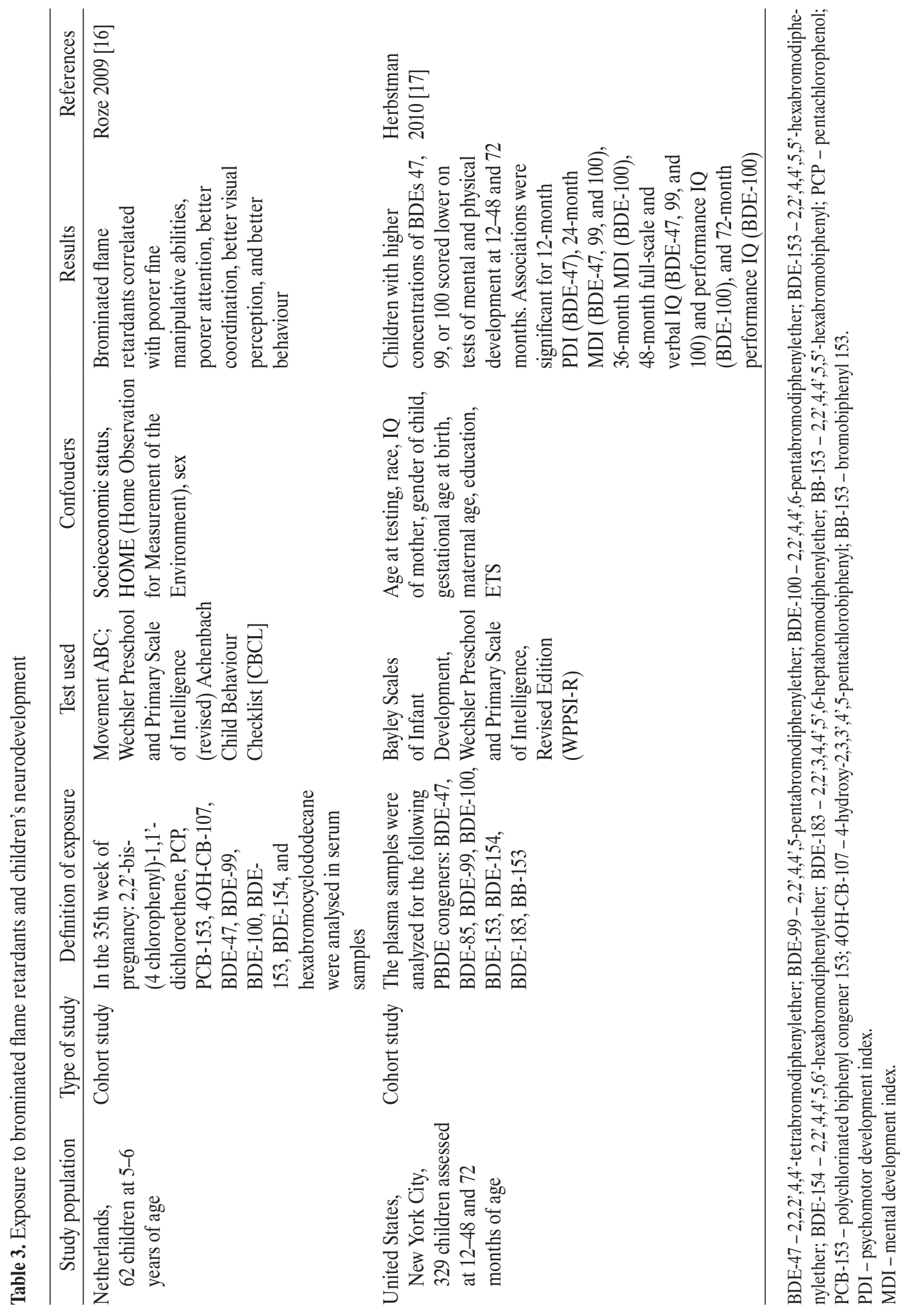




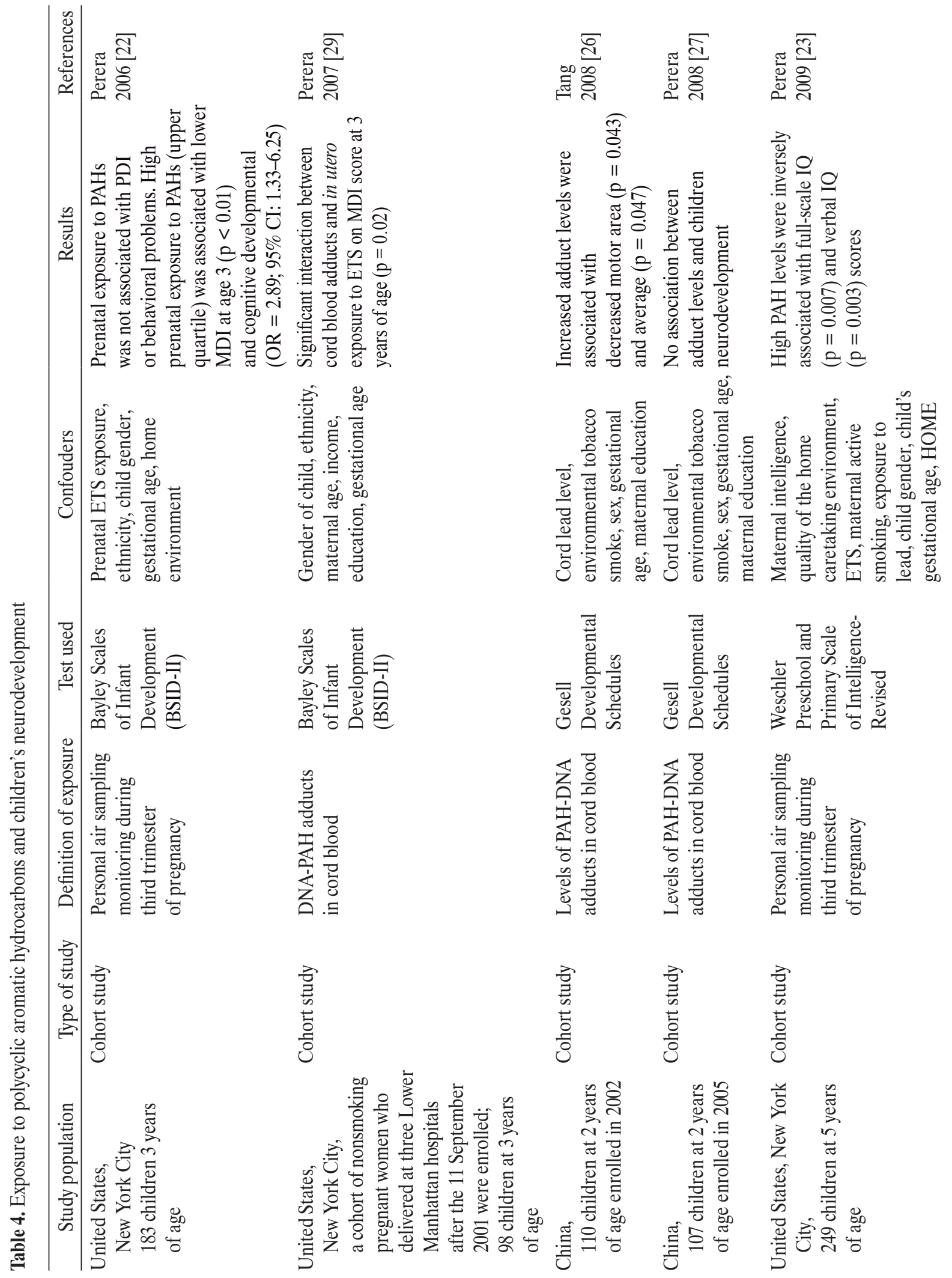



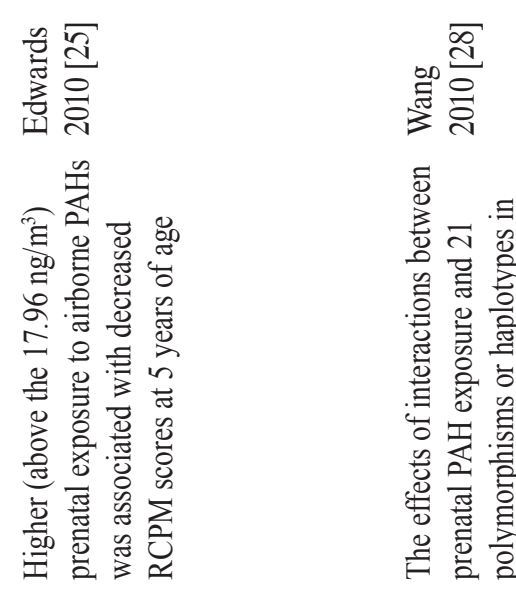

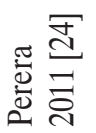

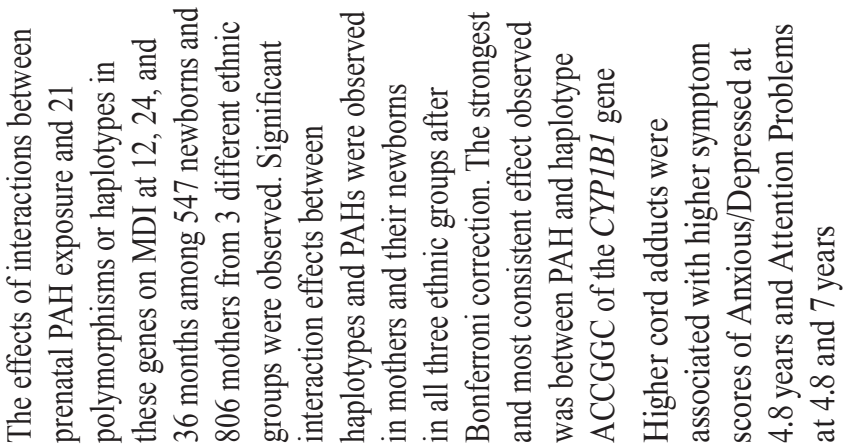
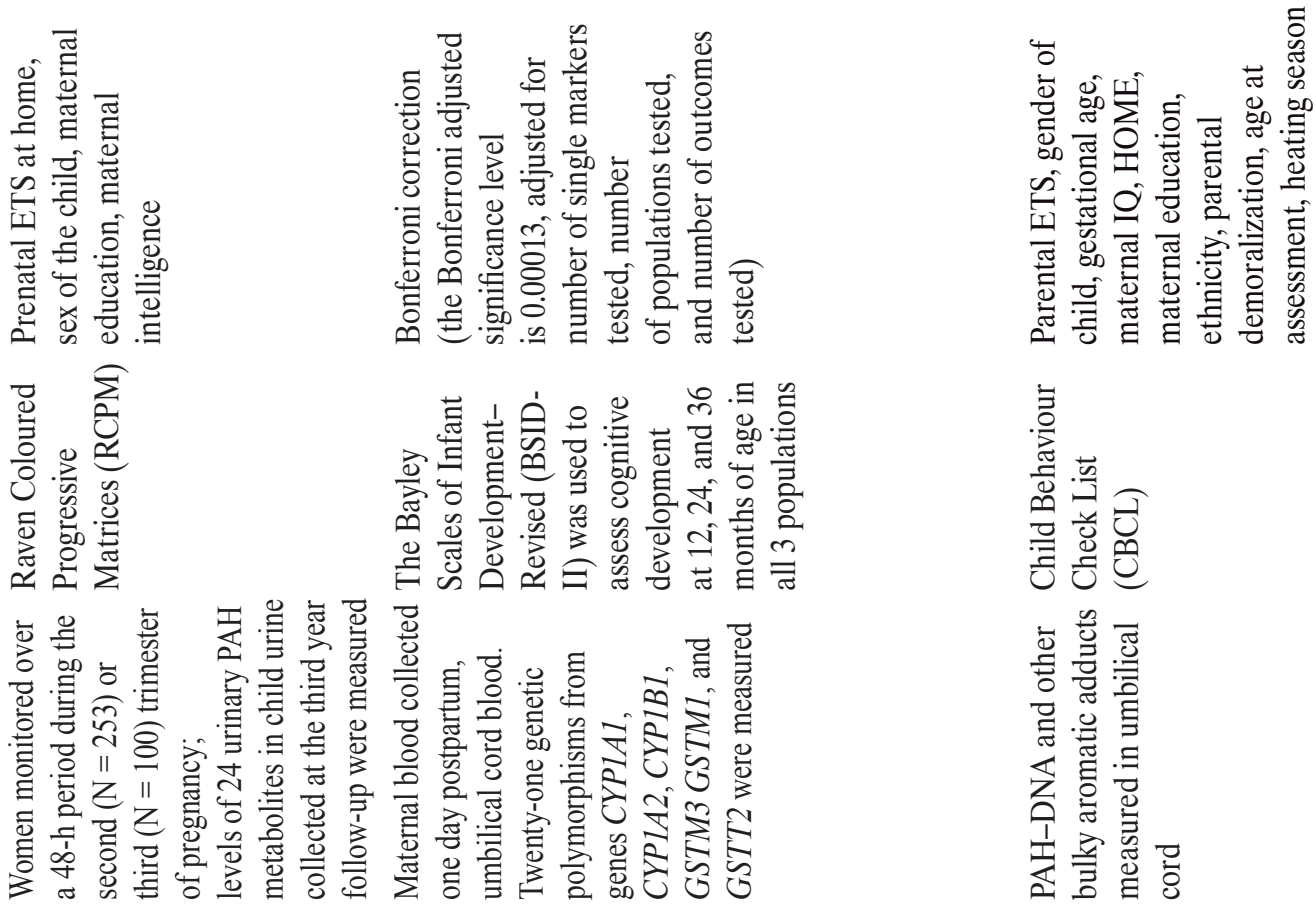

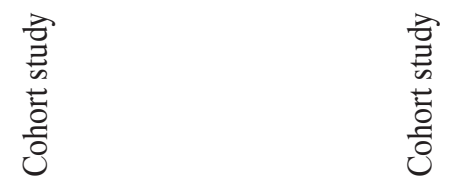
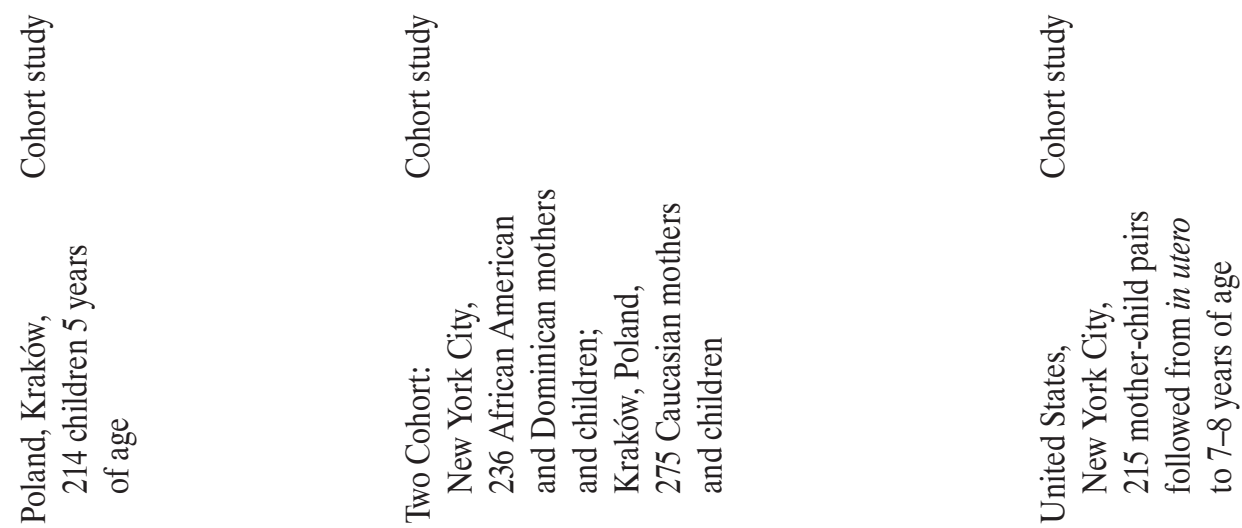
with high prenatal exposure $(\mathrm{OR}=2.89$; $95 \%$ CI: $1.33-$ 6.25) [22]. The same authors evaluated also prenatal exposure to airborne polycyclic aromatic hydrocarbons (PAHs) and child intelligence at age 5 years [23]. High PAH levels (above $17.96 \mathrm{ng} / \mathrm{m}^{3}$ ) were inversely associated with fullscale IQ ( $p=0.007)$ and verbal IQ $(p=0.003)$ scores [23]. The same cohort was followed to 7-8 years of age [24], adducts were measured in umbilical cord blood. Higher cord PAH-DNA and other bulky aromatic adducts were associated with higher symptom scores of anxious/depressed at 4.8 years and attention problems at 4.8 and 7 years, in children born to nonsmoking women, the women's smoking status was based on cotinine level in cord blood [24]. In the study performed in Poland, Kraków higher (> $17.96 \mathrm{ng} / \mathrm{m}^{3}$ ) prenatal exposure to airborne PAHs was associated with statistically significant reduction in scores on a test of nonverbal child intelligence in 5-year-old children. Children in the high-exposure group (> $17.96 \mathrm{ng} / \mathrm{m}^{3}$ ) scored lower on Raven Coloured Progressive Matrices $(\mathrm{RCPM})(\mathrm{p}=0.02)$ compared with less-exposed children $\left(\leq 17.96 \mathrm{ng} / \mathrm{m}^{3}\right)$. The relationship between prenatal airborne $\mathrm{PAH}$ and intelligence at 5 years of age remained significant after controlling for postnatal exposure to PAHs and ETS in the home. Further adjusting for maternal intelligence, lead, or dietary PAHs did not alter this association [25].

The effect of gene-PAH interactions on mental development in two cohort African American, Dominican in New York City and Caucasian Mothers and Newborns in Kraków, Poland [28] was assessed. The effects of interactions between prenatal PAH exposure and 21 polymorphisms or haplotypes in these genes on mental development index at 12, 24, and 36 months was observed. Those interactions remained significant after Bonferroni correction. The strongest and most consistent effect observed was between PAH and haplotype ACCGGC of the CYP1B1 gene [28].

Perera and co-workers (2007) examined also the combined exposure to environmental tobacco smoke (ETS) and PAH-DNA adducts in the study performed in New York City after the World Trade Center catastrophe [29]. After the 11 September 2001, a cohort of nonsmoking pregnant women who delivered at three Lower Manhattan hospitals were enrolled and child cognitive and motor development was assessed [29]. In multivariate analyses, a significant interaction between cord blood adducts and in utero exposure to ETS on mental development index score at 3 years of age $(p=0.02)$ was observed [29]. In the study conducted in Tongliang, Chongqing, China, where a seasonally operated coal-fired power plant was the major source of ambient PAHs, the association between prenatal exposure to this pollutant and child development measured in a cohort of nonsmoking women and their newborns enrolled in 2002 was assessed [26]. Increased PAH-DNA adduct levels were associated with decreased developmental quotients in motor area $(p=0.043)$, and average $(p=0.047)$ [26]. The next study performed in the same region of China in 2005 (after shutdown of the power plant) examined the exposure to PAHs and neurobehavioral development in children at 2 years of age [27]. Significant associations previously seen in 2002 [26] were not observed in the 2005 cohort [27].

The results of the presented studies provide evidence that environmental PAH exposure may adversely affect children's neurodevelopment [22,23,25]. One study indicated that Mental Development Index at young ages can be modulated by common genetic variants in the key genes CYP1A1, CYP1A2, CYP1B1, GSTT2, and GSTM1 [28]. In the studies in China enrolling nonsmoking women and their newborns in 2002 (before power plant was shutdown) and 2005 (after power plant was shutdown) the authors noticed that significant associations previously seen in 2002 between elevated adducts and decreased motor function were not observed in the 2005 cohort what was associated with the reduction of the PAH exposure [26,27]. 
EXPOSURE TO GAS COOKING AND CHILDREN'S NEURODEVELOPMENT

Gas cooking is a one of the main source of indoor air pollutants including nitrogen dioxide $\left(\mathrm{NO}_{2}\right)$ and particles. Homes with gas appliances can have $\mathrm{NO}_{2}$ concentrations twice as high as other homes and it may exceed the WHO guideline for average outdoor $\mathrm{NO}_{2}=40 \mu \mathrm{g} / \mathrm{m}^{3}$ [30]. Women and young children are especially exposed to indoor pollutants because they spend a larger part of the day at home and in the kitchen.

The first study analyzing the association of early-life exposure to gas appliances (and indoor $\mathrm{NO}_{2}$ ) with neuropsychological development was published by Morales et al. [31] (Table 5). The results from this prospective, population-based cohort study conducted in Spain, indicated that usage of gas appliances was inversely associated with cognitive outcomes ( $\beta$ coefficient $=-5.10 \mathrm{pts} ; 95 \% \mathrm{CI}$ : $-9.9-(-0.3))$, independent of social class and other confounders. $\mathrm{NO}_{2}$ concentrations were also associated with cognitive function $(\beta$ coefficient $=-0.3$ pts per $1 \mathrm{ppb}$, 95\% CI: $-0.48-(-0.07))$ which proved the above relationship. Those effects were modified by the Ile $105 \mathrm{Val}$ polymorphism in the detoxification gene glutathione-Stransferase P1.

The recently published results from prospective birth cohort study conducted on a bigger Spanish population (1887 mother-child pairs) indicated that gas cooking could be related to a small decrease in the mental development score compared with use of other cookers ( $\beta$ coefficient $=-2.5 \mathrm{pts} ; 95 \% \mathrm{CI}:-4.0-(-0.9))$ [30]. This association was independent of social class, maternal education, and other measured potential confounders (such as child gender, region, gestational age, type of house, maternal country of birth). The decrease was strongest in children tested after the age of 14 months ( $\beta$ coefficient $=-3.1 \mathrm{pts} ; 95 \% \mathrm{CI}:-5.1-(-1.1))$ than in children tested at younger age $(\beta$ coefficient $=-1.6 \mathrm{pts} ; 95 \% \mathrm{CI}$ : $-4.0-0.7)$ and when gas cooking was combined with less frequent use of an extractor fan ( $\beta$ coefficient $=-4.7 \mathrm{pts}$; 95\% CI: -7.6-(-1.7)) [30].

The results of presented two studies indicate a small adverse effect of indoor air pollution from gas cookers on child development.

\section{SUMMARY OF THE STUDY RESULTS}

Recent studies strongly suggest that the developing nervous system is particularly vulnerable to insult from low levels of exposure to widespread environmental contaminants such as: phthalates, bisphenol A, brominated flame retardants, polycyclic aromatic hydrocarbons and gas cooking.

In all the studies, exposure to phthalates was associated with neurodevelopmental disorders: conduct problems [9], quality of alertness among girls [5], decreased (less masculine) composite score in boys [10] and lower concentrations and vocabulary score among boys [7] and children's social impairment [11]. The results of the studies on exposure to bisphenol A and children's neurodevelopment are inconsistent. Studies among children at 2 years of age have indicated the association between prenatal BPA concentrations and externalizing scores in females [13] and at 3 years of age with higher scores for measures of anxiety, hyperactivity, emotional control, and behavioral inhibition [13]. On the other hand, no significant associations with neurobehavioral outcomes at 5-week infants [6] and social impairment at 7 and 9 years of age were observed [11].

The result of the presented studies indicate that exposure to brominated flame retardants may result in impaired children's neurodevelopment manifested by poorer fine manipulative abilities, poorer attention [16] and lower scores on tests of mental and physical development [17]. Also the environmental exposure to PAHs may adversely affect children's neurodevelopment [22,23,25]. Mental Development Index at young ages can be modulated by common genetic variants in the key genes CYP1A1, 


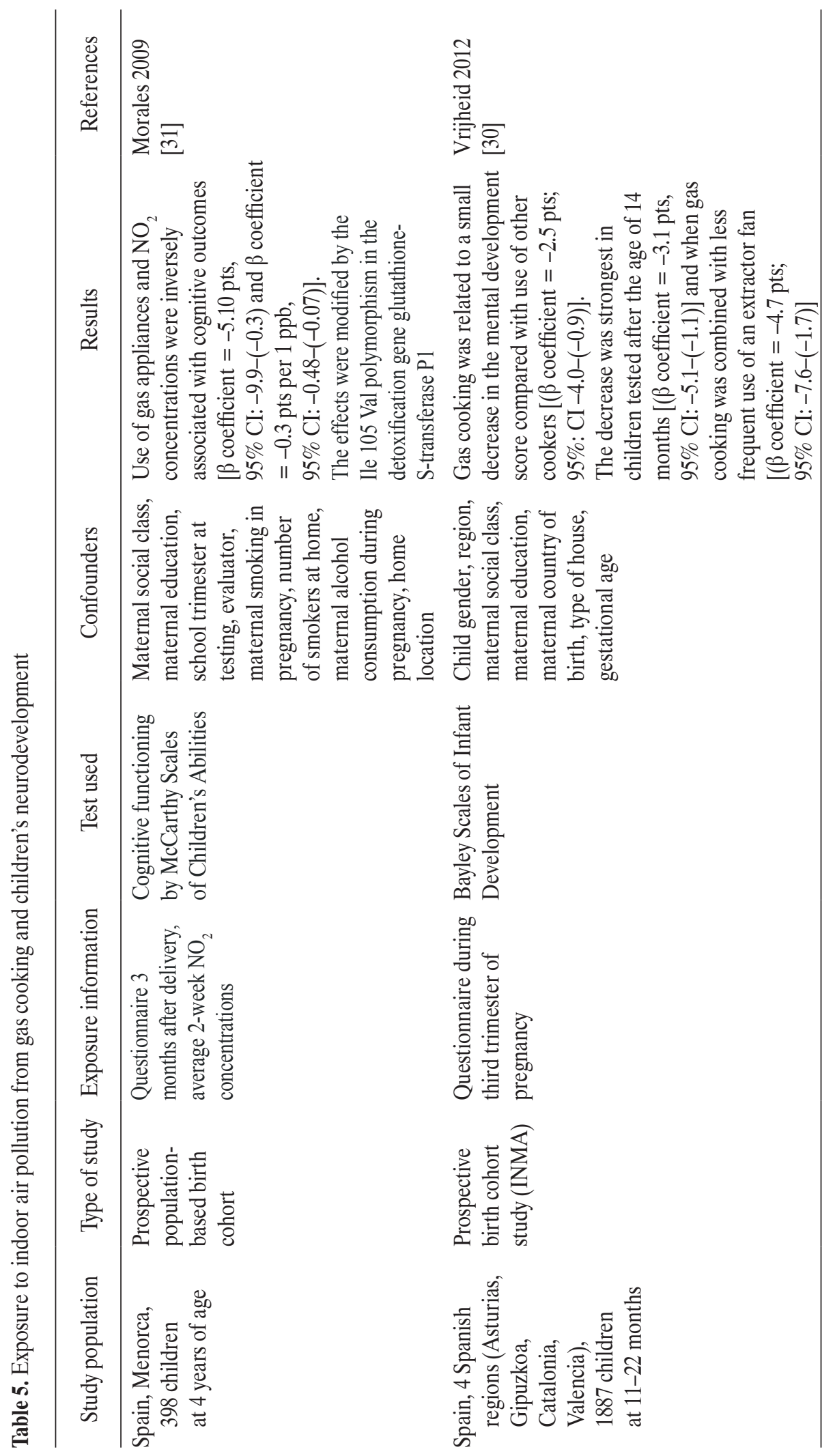


CYP1A2, CYP1B1, GSTT2, and GSTM1 [28]. Significant associations between elevated adducts and decreased motor functions observed before the power plant was closed, were no longer observed after the shutdown in the study performed in China [26,27].

Two studies indicate a small adverse effect of indoor air pollution from gas cookers on child cognitive development [30,31]. Given the consistency of exposure over time within families, it is not possible to determine how timing of exposure (prenatal versus postnatal) might affect the association.

When reviewing the epidemiological studies on the influence of exposure to environmental factors and neurodevelopment in children, it is important to take into account the current limitations of these studies resulting from inadequacies in exposure assessment, critical window of exposure and the mechanism by which the exposure can be associated with the outcome.

\section{THE MECHANISM OF EXPOSURE} TO ENVIRONMENTAL FACTORS

\section{AND CHILDREN'S NEURODEVELOPMENT}

The biological mechanism that might cause negative effects on child development of most reviewed environmental factors: phthalates, BPA, brominated flame retardants, gas cooking and PAHs on neural development has not been established yet. Phthalates are suspected of interfering with the thyroid hormone system [32] or the lipid signal transduction pathways alter lipid metabolism in the brain [33]. They have been shown to decrease the number of midbrain dopaminergic neurons, tyrosine hydroxylase biosynthetic activity [34], tyrosine hydroxylase immunoreactivity [35] and exhibit antiandrogenic activity [36], which may interfere with the regulation of normal foetal brain development [37].

Exposure to endocrine-disrupting compounds such as BPA may alter the course of normal neurodevelopment by the impact on neuronal connectivity, distribution of serotinergic fibers, synaptic function, and dendritic length [38].

A number of potential mechanisms have been proposed to explain the cognitive and locomotive deficits in animals after brominated flame retardants exposure including direct neurotoxic effect on neuronal and glial cells [39]. In addition, those compounds can interfere with thyroid hormone pathways [40].

PAHs have been shown to be neurodevelopmental toxicants in experimental studies [19-21]. Suggested mechanisms include endocrine disruption [41-43], binding to receptors for placental growth factors resulting in decreased exchange of oxygen and nutrients [44], binding to the human Ah receptor to induce P450 enzymes, DNA damage resulting in activation of apoptotic pathways [45-47], epigenetic effects [48], or oxidative stress due to inhibition of the brain antioxidant scavenging system [49].

Little is known about direct neurotoxic effects of $\mathrm{NO}_{2}$, but speculations include a possible mechanism through the peroxidation of brain lipids or through interference with dopamine biosynthesis [30,31].

\section{CONFOUNDING FACTORS}

The results of the most of presented studies were adjusted for well-known confounders. Bellinger (2004) noticed that confounders that were thought to confound other environmental toxin-neurodevelopment relations should be included into the analysis [50]. Those confounders are as follows: maternal and child demographic factors such as maternal age, race, education, marital status, annual household income and child sex. Other factors that can have an impact on child neurodevelopment are: maternal depression during pregnancy that could be included and measured by the Beck Depression Inventory (BDI-II) [51] and caregiving environment that could be measured by administering the Home Observation for Measurement 
of the Environment (HOME) Inventory [52]. The authors also pointed maternal IQ as the confounder that should be included in the analysis.

The major potential confounders in studies of child neurobehavior are well-known, and most studies at least try to assess them. The concern is generally not that such factors are unmeasured, but that they are not measured well, like stress, home environment, social class.

\section{EXPOSURE ASSESSMENT}

Exposure assessment is a crucial part of any area of environmental epidemiology.

Measurements of contaminants in urine, blood, semen, amniotic fluid, and breast milk usually provide the best assessment of exposure [53].

Exposure to phthalates in almost all presented studies was based on specific biomarkers of exposure mainly in urine [5-11]. As phthalates are metabolized to their monoesters within a few hours or days $[54,55]$, urinary phthalate monoesters are considered good biomarkers for assessing phthalate exposure in humans [55-58]. A recent review by Teitelbaum et al. of sources of variability in biomarkers of environmental exposures in minority children, including phthalates also confirms that a single spot urine sample is sufficiently representative of exposure over a 6-month period to warrant its use as an exposure estimate in epidemiological studies [59].

Exposure assessment in all BPA studies was based on urine samples [6,11,13-15]. Because of BPA's short elimination half-life [60], spot urinary BPA concentrations primarily reflect the exposure that occurred within a relatively short period before urine collection [61]. Nonetheless, a single spot urine sample may provide a somewhat reliable ranking to classify a person's BPA exposure for up to several months [59,62], even given the considerable temporal variability of urinary BPA concentrations within and between subjects [63].
Brominated flame retardants were analyzed in plasma samples [17] and in blood serum [16].

Exposure to PAHs were measured by personal air monitoring during pregnancy $[22,24,25]$ and 24 urinary PAH metabolites in child urine [25]. The published data evaluating the PAH exposure among pregnant women is also based on PAH-DNA adducts measured in cord blood [24,26,27,29].

In the studies performed by Perera $(2006,2009)$ [22,23] and Edwards (2010) [25], the authors considered the single monitoring time point to be a reasonable indicator of prenatal exposure via inhalation over the last two trimesters of pregnancy because measurements during the second and third trimesters were correlated.

PAH-DNA adduct levels reflect individual variation in exposure, absorption, metabolic activation, and DNA repair, the level of PAH-DNA adducts provides a biologically relevant dosimeter of exposure. As there is a hypothesis that adduct formation resulting in mutations or apoptosis during critical windows of brain development might adversely affect child development, adducts can be considered as a biologically relevant measure of exposure [26]. The assessment of exposure to indoor air pollution from gas cooking was based on questionnaire data [30] and indoor $\mathrm{NO}_{2}$ concentrations [31]. The published studies have not measured particles or other gas-cooking-related pollutants and have not collected the information that can influence the exposure such as the time spent cooking or the location of the kitchen. Better characterization of gas-cooking-related exposures, preferably through the measurement of associated pollutants will be important in future studies.

\section{WINDOWS OF EXPOSURE}

The effects produced by a neurotoxic agent depend on a number of factors: the timing and duration of exposure, the distribution of the toxicant in various parts of 
the nervous system, the amount or concentration of the agent in nervous tissue, and the ability of a toxicant to interfere with specific developmental processes. Therefore, the neurodevelopmental consequences of exposure to different neurotoxic agents would be expected to vary, depending on the agent, the developmental stages of exposure, and the pattern and duration of exposure during those stages $[64,65]$. An environmental neurotoxic agent may produce impairment in different functional domains depending on the time of exposure. For example, the same exposure at different points in development could result in an adverse effect on motor systems versus memory or executive functions. Similarly, exposures at different concentrations or for different lengths of time could potentially produce differential effects. Therefore, the constellation of observed effects should not be expected to be the same in different children exposed to the same neurotoxic agent [36].

In most of the presented studies exposure to phthalates, bisphenol A, brominated flame retardants and PAHs was assessed prenatally (during pregnancy). One study on exposure to phthalates and neurodevelopment assessed the exposure postanally among school children [7].

As the exposure to phthalates, bisphenol A and PAHs is very common and can occur every day, we cannot be sure that the exposure measured during pregnancy is associated with the observed neurodevelopmental effects. The exposure during unmeasured time can also be associated with the outcome.

\section{CONCLUSION}

The results of the reviewed studies suggest that exposure to phthalates, BPA, brominated flame retardants, PAHs and gas cooking may affect children neurodevelopment. Exposure to a number of environmental agents with neurotoxic effects can result in a spectrum of adverse outcomes from severe mental retardation and disability, to more subtle changes in function depending on the agent, timing and target tissue dose.

Taken together, the results of many emerging studies on the hazards associated with early exposure to neurotoxic chemicals widespread in the environment should sound the alarm for clinicians, researchers, public health professionals and policy makers.

\section{REFERENCES}

1. Rauh VA, Horton MK, Miller RL, Whyatt RM, Perera F. Neonatology and the environment: impact of early exposure to airborne environmental toxicants on infant and child neurodevelopment. Neoreviews 2010;11:363-9.

2. Plomin R, Owen M, McGuffin P. The genetic basis of complex human behaviors. Science 1994;264:1733-9.

3. Api AM. Toxicological profile of diethyl phthalate: A vehicle for fragrance and cosmetic ingredients. Food Chem Toxicol 2001;39:97-108.

4. Tanaka T. Reproductive and neurobehavioral effects of bis(2-ethylhexyl) phthalate (DEHP) in a cross-mating toxicity study of mice. Food Chem Toxicol 2005;43:581-9.

5. Engel SM, Zhu C, Berkowitz GS, Calafat AM, Silva MJ, Miodovnik A, et al. Prenatal phthalate exposure and performance on Neonatal Behavioral Assessment Scale in multiethnic birth cohort. Neurotoxicology 2009;30:522-8.

6. Yolton K, Xu Y, Strauss D, Altaye M, Calafat A, Khoury J. Prenatal exposure to bisphenol $A$ and phthalates and infant neurobehavior. Neurotoxicol Teratol 2011;33:558-66.

7. Cho SC, Bhang SY, Hong YC, Shin MS, Kim BN, Kim JW, et al. Relationship between environmental phthalate exposure and the intelligence of school-age children. Environ Health Perspect 2010;118(7):1027-32.

8. Kim Y, Ha EH, Kim EJ, Park H, Ha M, Kim JH, et al. Prenatal exposure to phthalates and infant development at 6 months: Prospective Mothers and Children's Environmental Health (MOCEH) Study. Environ Health Perspect 2011;119(10):1495-500. 
9. Engel SM, Miodovnik A, Canfield RL, Zhu C, Silva MJ, Calafat AM, et al. Prenatal phthalate exposure is associated with childhood behavior and executive functioning. Environ Health Perspect 2010;118(4):565-71.

10. Swan SH, Liu F, Kruse RL, Wang C, Redmon JB, Sparks A, et al. Prenatal phthalate exposure and reduced masculine play in boys. Int J Androl 2009;32:1-9.

11. Miodovnik A, Engel SM, Zhu C, Ye X, Soorya LV, Silva MJ, et al. Endocrine disruptors and childhood social impairment. Neurotoxicology 2011;32:261-7.

12. Kang JH, Kondo F, Katayama Y. Human exposure to bisphenol A. Toxicology 2006;226(2-3):79-89.

13. Braun JM, Yolton K, Dietrich KN, Horunung R, Ye X, Calafat AM, et al. Prenatal bisphenol A exposure and early childhood behavior. Environ Health Perspect 2009;117(12):1945-52.

14. Braun JM, Kalkbrenner AM, Calafat AM, Yolton K, Ye X, Dietrich KN, et al. Impact of Early-life bisphenol A exposure on behavior and executive function in children. Pediatrics 2011;128(5):873-82.

15. Sathyanarayana S, Braun JM, Yolton K, Liddy S, Lanphear BP. Case report: high prenatal bisphenola exposure and infant neonatal neurobehavior. Environ Health Perspect 2011;119(8):1170-5.

16. Roze E, Meijer L, Bakker A, Van Braeckel KNJA, Sauer PJJ, Bos AF. Prenatal exposure to organohalogens, including brominated flame retardants, influences motor, cognitive and brhavioral performance at school age. Environ Health Perspect 2009;117(12):1953-8.

17. Herbstman JB, Sjodin A, Kurzon M, Lederman SA, Jones RS, Rauh V, et al. Prenatal exposure to PBDEs and neurodevelopment. Environ Health Perspect 2010;118(5):712-7.

18. Boström CE, Gerde P, Hanberg A, Jernström B, Johansson C, Kyrklund T, et al. Cancer risk assessment, indicators, and guidelines for polycyclic aromatic hydrocarbons in the ambient air. Environ Health Perspect 2002;110(Suppl 3):451-88.

19. Saunders CR, Das SK, Ramesh A, Shockley DC, Mukherjee S. Benzo(a)pyrene-induced acute neurotoxicity in the F-344 rat: role of oxidative stress. J Appl Toxicol 2006;26:427-38.
20. Šrám RJ, Binkova B. Molecular epidemiology studies on occupational and environmental exposure to mutagens and carcinogens, 1997-1999. Environ Health Perspect 2000;108:57-70.

21. Wormley DD, Ramesh A, Hood DB. Environmental contaminant-mixture effects on CNS development, plasticity, and behavior. Toxicol Appl Pharmacol 2004;197:49-65.

22. Perera FP, Rauh V, Whyatt RM, Tsai WY, Tang D, Diaz D, et al. Effects of prenatal exposure to airborne polycyclic aromatic hydrocarbons on neurodevelopment in the first 3 years of life among inner-city children. Environ Health Perspect 2006;114(8):1287-92.

23. Perera FP, Li Z, Whyatt R, Hoepner L, Wang S, Camann D, et al. Prenatal airborne polycyclic aromatic hydrocarbon exposure and child IQ at age 5 years. Pediatrics 2009;124(2):195-202.

24. Perera FP, Wang S, Vishnevetsky J, Zhang B, Cole KJ, Tang D, et al. Polycyclic aromatic hydrocarbons-aromatic DNA adducts in cord blood and behavior scores in New York city children. Environ Health Perspect 2011;119(8):1176-81.

25. Edwards SC, Jedrychowski W, Butscher M, Camann D, Kieltyka A, Mroz E, et al. Prenatal exposure to airborne polycyclic aromatic hydrocarbons and children's intelligence at 5 years of age in a prospective cohort study in Poland. Environ Health Perspect 2010;118(9):1326-31.

26. Tang D, Li T, Liu JJ, Zhou Z, Yuan T, Chen Y, et al. Effects of prenatal exposure to coal-burning pollutants on children's development in China. Environ Health Perspect 2008;116(5):674-9.

27. Perera F, Li T, Zhou Z, Yuan T, Chen Y, Qu L, et al. Benefits of reducing prenatal exposure to coal-burning pollutants to children's neurodevelopment in China. Environ Health Perspect 2008;116(10):1396-400.

28. Wang S, Chanock S, Tang D, Li Z, Edwards S, Jedrychowski W, et al. Effect of gene-environment interactions on mental development in African American, Dominican, and Caucasian mothers and newborns. Ann Hum Genet 2010;74:46-56.

29. Perera FP, Tang D, Rauh V, Tu HY, Tsai WY, Becker M, et al. Relationship between polycyclic aromatic hydrocarbon-DNA adducts, environmental tobacco smoke, and child development 
in the World Trade Center Cohort. Environ Health Perspect 2007;115(10):1497-502.

30. Vrijheid M, Martinez D, Aguilera I, Bustamante M, Ballester F, Estarlich M, et al. INMA Project. Indoor air pollution from gas cooking and infant neurodevelopment. Epidemiology 2012;23(1):23-32.

31. Morales E, Julvez J, Torrent M, de Cid R, Guxens M, Bustamante M, et al. Association of early-life exposure to household gas appliances and indoor nitrogen dioxide with cognition and attention behavior in preschoolers. Am J Epidemiol 2009;169(11):1327-36.

32. Ghisari M, Bonefeld-Jorgensen EC. Effects of plasticizers and their mixtures on estrogen receptor and thyroid hormone functions. Toxicol Lett 2009;189:67-77.

33. Xu Y, Agrawal S, Cook TJ, Knipp GT. Di-(2-ethylhexyl)phthalate affects lipid profiling in fetal rat brain upon maternal exposure. Arch Toxicol 2007;81:57-62.

34. Tanida T, Warita K, Ishihara K, Fukui S, Mitsuhashi T, Sugawara $\mathrm{T}$, et al. Fetal and neonatal exposure to three typical environmental chemicals with different mechanisms of action: mixed exposure to phenol, phthalate, and dioxin cancels the effects of sole exposure on mouse midbrain dopaminergic nuclei. Toxicol Lett 2009;189(1):40-7.

35. Ishido M, Masuo Y, Kunimoto M, Oka S, Morita M. Bisphenol A causes hyperactivity in the rat concomitantly with impairment of tyrosine hydroxylase immunoreactivity. J Neurosci Res 2004;76(3):423-33.

36. Borch J, Axelstad M, Vinggaard AM, Dalgaard M. Diisobutyl phthalate has comparable anti-androgenic effects to di-n-butyl phthalate in fetal rat testis. Toxicol Lett 2006;163(3):183-90.

37. Colborn T. Neurodevelopment and endocrine disruption. Environ Health Perspect 2004;112:944-9.

38. Palanza P, Morellini F, Parmigiani S, vom Saal FS. Prenatal exposure to endocrine disrupting chemicals: effects on behavioral development. Neurosci Biobehav Rev 1999;23(7): 1011-27.

39. Costa LG, Giordano G, Tagliaferri S, Caglieri A, Mutti A. Polybrominated diphenyl ethers (PBDE) flame retardants: environmental contamination, human body burden and potential adverse health effects. Acta Biomed 2008;79(3):172-83.

40. Legler J. New insights into the endocrine disrupting effects of brominated flame retardants. Chemosphere 2008;73(2): 216-22.

41. Archibong $\mathrm{AE}$, Inyang $\mathrm{F}$, Ramesh $\mathrm{A}$, Greenwood $\mathrm{M}$, Nayyar T, Kopsombut P, et al. Alteration of pregnancy related hormones and fetal survival in F-344 rats exposed by inhalation to benzo(a)pyrene. Reprod Toxicol 2002;16:801-8.

42. Bui QQ, Tran MB, West WL. A comparative study of the reproductive effects of methadone and benzo(a)pyrene in the pregnant and pseudopregnant rat. Toxicol 1986;42(2-3): 195-204.

43. Takeda K, Tsukue N, Yoshida S. Endocrine-disrupting activity of chemicals in diesel exhaust and diesel exhaust particles. Environ Sci 2004;11:33-45.

44. Dejmek J, Solansky I, Beneš I, Lenícek J, Šrám RJ. The impact of polycyclic aromatic hydrocarbons and fine particles on pregnancy outcome. Environ Health Perspect 2000;108: 1159-64.

45. Meyn MS. Ataxia-telangiectasia and cellular responses to DNA damage. Cancer Res 1995;55:5991-6001.

46. Nicol CJ, Harrison ML, Laposa RR, Gimelshtein IL, Wells PG. A teratologic suppressor role for $p 53$ in benzo[a]pyrene-treated transgenic p53-deficient mice. Nat Genet 1995;10:181-7.

47. Wood KA, Youle RJ. The role of free radicals and $p 53$ in neuron apoptosis in vivo. J Neurosci 1995;15:5851-7.

48. Wilson VL, Jones PA. Inhibition of DNA methylation by chemical carcinogens in vitro. Cell 1983;32(1):239-46.

49. Lundqvist C, Zuurbier M, Leijs M, Johansson C, Ceccatelli S, Saunders M, et al. The effects of PCBs and dioxins on child health. Acta Paediatr 2006;453(Suppl 95):55-64.

50. Bellinger DC. Assessing environmental neurotoxicant exposure and child neurobehavior - Confunded by confounding? Epidemiology 2004;15(4):383-4.

51. Beck AT, Steer RA, Brown GK. Manual for the Beck Depression Inventory-II. San Antonio, TX: Psychological Corporation; 1996. 
52. Caldwell BM, Bradley RH. Home observation for measurement of the environment: administration manual. Little Rock, AR: University of Arkansas; 2003.

53. Latini G, Felice CD, Presta G, Del Vecchio A, Paris I, Ruggieri $\mathrm{F}$, et al. In utero exposure to di-(2-ethylhexyl) phthalate and duration of human pregnancy. Environ. Health Perspect 2003;111:1783-5.

54. Dirven HA, van den Broek PH, Arends AM, Nordkamp HH, de Lepper AJ, Henderson PT, et al. Metabolites of the plasticizer di(2-ethylhexyl) phthalate in urine samples of workers in polyvinylchloride processing industries. Int Arch Occup Environ Health 1993;64:549-54.

55. Koch HM, Bolt HM, Angerer J. Di(2-ethylhexyl)phthalate (DEHP) metabolites in human urine and serum after a single oral dose of deuterium-labelled DEHP. Arch Toxicol 2004;78:123-30.

56. Hauser R, Meeker JD, Park S, Silva MJ, Calafat AM. Temporal variability of urinary phthalate metabolite levels in men of reproductive age. Environ Health Perspect 2004;112:1734-40.

57. Huang PC, Kuo PL, Guo YL, Liao PC, Lee CC.Associations between urinary phthalate monoesters and thyroid hormones in pregnant women. Hum Reprod 2007;22(10):2715-22.

58. Silva MJ, Reidy JA, Herbert AR, Preau JL Jr, Needham LL, Calafat AM. Detection of phthalate metabolites in human amniotic fluid. Bull Environ Contam Toxicol 2004;72:1226-31.
59. Teitelbaum SL, Britton JA, Calafat AM, Ye X, Silva MJ, Reidy JA, et al. Temporal variability in urinary concentrations of phthalate metabolites, phytoestrogens and phenols among minority children in the United States. Environ Res 2008;106(2):257-69.

60. Völkel W, Colnot T, Csanady GA, Filser JG, Dekant W. Metabolism and kinetics of bisphenol $A$ in humans at low doses following oral administration. Chem Res Toxicol 2002;15(10):1281-7.

61. Koch HM, Calafat AM. Human body burdens of chemicals used in plastic manufacture. Biol Sci 2009;364(1526):2063-78.

62. Mahalingaiah S, Meeker JD, Pearson KR, Calafat AM, Petrozza J, Hauser R. Temporal variability and predictors of urinary bisphenol A concentrations in men and women. Environ Health Perspect 2008;116(2):173-8.

63. Arakawa C, Fujimaki K, Yoshinaga J, Imai H, Serizawa S, Shiraishi H. Daily urinary excretion of bisphenol A. Environ Health Prev Med 2004;9(1):22-6.

64. Dietrich KN, Eskenazi B, Schantz S, Yolton K, Rauh VA, Johnson CB, et al. Principles and Practices of neurodevelopmental assessment in children: lessons learned from the Centers for Children's Environmental Health and Disease Prevention Research. Environ Health Perspect 2005;113(10):1437-46.

65. Rice D, Barone SJ. Critical periods of vulnerability for the developing nervous system: evidence from humans and animal models. Environ Health Perspect 2000;103(Suppl 3):511-33.

This work is available in Open Access model and licensed under a Creative Commons Attribution-NonCommercial 3.0 Poland License - http://creativecommons.org/ licenses/by-nc/3.0/pl/deed.en. 